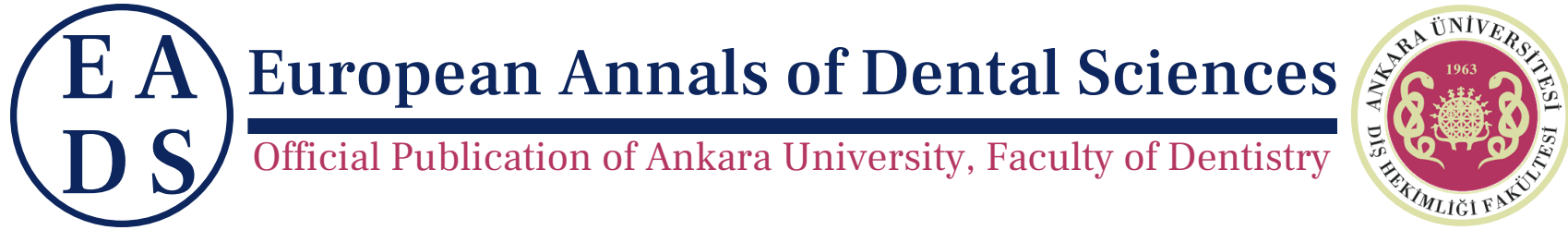

EADS, 2021, $48(1), 40-45$

\title{
Management of Emergency Cases in Endodontics Practice During The Covid-19 Pandemic: A Literature Review
}

\author{
Aysenur Oncu ${ }^{(1, *}$, Emine Odabasi Tezer ${ }^{1}$ and Berkan Celikten ${ }^{2} 2$ \\ ${ }^{1}$ DDs, Ankara University, Faculty of Dentistry, Department of Endodontics, Ankara, Turkey and ${ }^{2}$ DDs, PhD, \\ Ankara University, Faculty of Dentistry, Department of Endodontics, Ankara, Turkey \\ *Corresponding Author; dtaysenuroncu@gmail.com
}

\begin{abstract}
The aim of this review is to evaluate emergencies and treatment approaches encountered in the endodontics clinic during the Covid-19 epidemic process. For this study, articles on dentistry related to Covid-19 in PubMed and Google Scholar databases were searched. Clinicians should know the infection transmission routes and prevention methods well. In this duration, it is substantial to distinguish which case is urgent and to complete the necessary treatment in a short time. This paper presents useful suggestions for dental emergency practice.
\end{abstract}

Key words: covid-19; emergency; endodontics

\section{Introduction}

Covid-19 disease caused by coronavirus emerged in 2019 and spread rapidly around the world. This virus, which causes the acute respiratory syndrome, has seriously threatened human health and played a main role in the pandemic. ${ }^{1}$ The disease, which is extremely contagious, has importantly affected the functioning of the medical sector as well as disrupting the routine life flow. The coronavirus that has entered the body, is existed plenty amount in the patient's nasal area and saliva in the oral cavity. Moreover, it is believed to be transmitted by droplet infection. ${ }^{2}$ This situation poses a great risk for both patients and dentists during dental treatments. Because the operator works at a close distance to the patient within certain limits while applying treatment, and aerosol is formed during many process. ${ }^{3}$ Therefore, in dental clinics, emergency cases should be selected only, and procedures should be completed minimal period. Clinicians compulsory to adapt to these new conditions and have the ability to decide which cases to intervene. ${ }^{4}$ In dentistry, events such as irreversible pulpits, acute abscess, maxillofacial trauma are considered as emergencies (Figure 1). Emergency management in endodontics is normally difficult, ${ }^{5}$ but it has become a very hard challenging to overcome in the Covid-19 duration. Irreversible pulpitis can occurs in teeth with deep dentin caries, with severe, throbbing and intolerable pain. ${ }^{6}$ Patients who apply to the clinic with these symptoms usually have anxiety and stress due to pain. Acute abscesses caused by necrotic dental pulp or periodontal tissue diseases are signs of swelling, redness and pain. ${ }^{7}$ On the other hand, acute exacerbations called flare-up may occur after previous root canal treatment. ${ }^{8}$ Dental traumas include various injuries such as enamel, dentin, root fractures, luxation, and avulsion. ${ }^{9}$ There are treatment protocols prepared for all conditions mentioned in the literature. However, during the epidemic period, these applications should be taken more carefully than before in order to avoid the contagiousness of the infection. In this review study, emergencies and infection prevention methods encountered in dental practice were evaluated.

\section{Covid-19 pandemic}

Although there are researches that have been seen in other continents before, it is accepted that the first Covid-19 cases appeared in Wuhan, China. In a short time, the Covid-19 outbreak, which spread to a wide area in more than one country or continent in the world, was declared as a pandemic. It was determined that the causative agent of the disease was coronavirus (SARS - CoV -2), which was a member of the RNA virus family, and that bats were the source of this at the beginning ${ }^{10}$. Angiotensin converting enzyme 2 (ACE 2) in the lungs is assumed to be the receptor for SARS - CoV. ${ }^{11}$ After SARS - CoV 


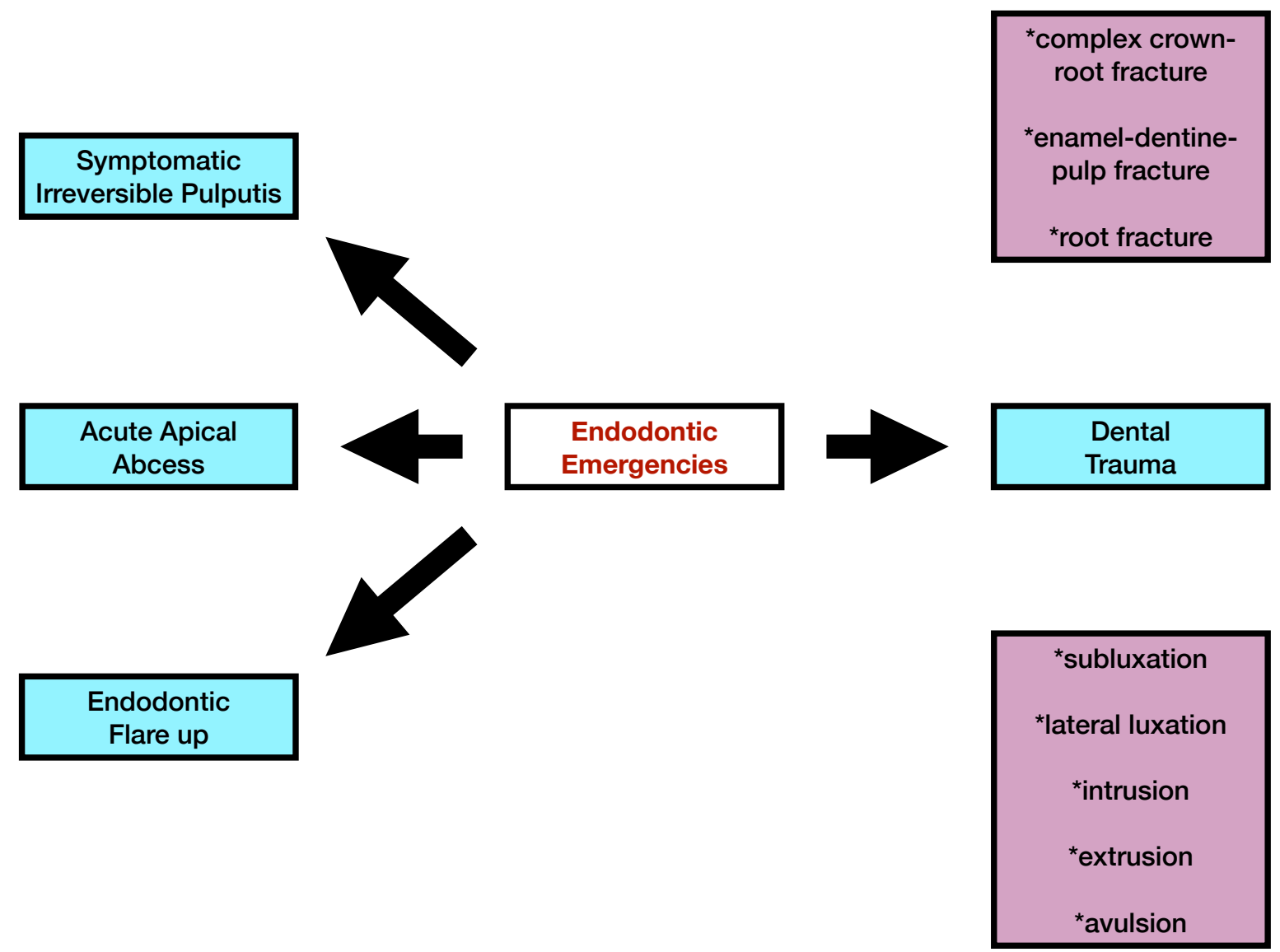

Figure 1. Emergencies in endodontic practice.

-2 binds to ACE-2, it can trigger a series of systemic reactions by causing high levels of ACE-2 expression that can damage alveolar cells. ${ }^{12}$ Detecting of cases is important to reduce the pace of the outbreak and keep it under control. Some laboratory tests can be used in the diagnosis of the disease. Reverse transcription quantitation (PCR) is a nucleic acid testing method based on the laboratory examination of nasopharyngeal or oropharyngeal swab samples. ${ }^{13,14}$ Also, frosted-glass opacities are typically found in the chest on computed tomography images.

Patients diagnosed with Covid-19 may have symptoms of high fever, cough, headache, joint pain, diarrhea, loss of smell and taste sense. ${ }^{2}$ It has been observed that the disease can progress with a few symptoms or can be overcome without feeling any of them. However, it is not known exactly what effects it will have on the organism in the future. The illness duration may be more severe in people with weak immune systems, the elderly population and patients with systemic chronic diseases. Covid-19 can cause severe breathing difficulties in people with chronic obstructive pulmonary disease, asthma and allergic lung problems. The long incubation period ( 2 weeks) of the disease increases the risk of transmission. ${ }^{15}$ Although it is thought that Covid-19 is mainly transmitted by droplet infection, the contagion can also be spread by direct contact to the nasal and oral mucosa. The risk of contamination is particularly high for dentists working in the mouth area. The aerosol formed in many dental applications disperses into the indoor air and allows an environment conducive to contagion.
Endodontic emergencies and methods of protection from infection in practice

During the Covid-19 pandemic, endodontic treatments should be evaluated according to their urgency. ${ }^{16}$ Close contact between the patient and physician, which is inevitable during treatment, may result in possible contamination, cross-infection and spread of the virus. In this process, the main complaints of the patients should be questioned and the differences between the emergency and urgency situations should be revealed. To determine the real emergencies, the following inquiries should be made: ${ }^{17}$

- Does your pain interrupt your sleep, eating, working life or other daily routines?

- How long have you been in pain?

- Have you taken any medication? Did the medicine have an effect?

In true pain conditions, pain obstacles to the patient's routine activities extend from 2 to 3 days, which is considered usual for normal acute inflammatory condition, and using analgesics inadequate (Table 1).

At the end of the interview, medication should be prescribed to the patient for treatment considered elective. However, in real emergencies, the physician should make a preliminary diagnosis and request an extra oral view such as cone-beam computed tomographic examination from the required area. Also, an appointment should be made for the nearest time $2,18,19$

On the other hand, dental abscesses, which are characterized by swelling of the face or oral tissues, require alert. It can cause fever, lymphoadonapathy and dysphagia with accompa- 
Table 1. Protocol for treatment approach to emergencies in endodontics.

\begin{tabular}{cl}
\hline \multirow{2}{*}{ Symptomatic Irreversible Pulpitis } & $\begin{array}{l}\text { Mild symptoms: prescribe appropriate analgesics } \\
\text { Moderate symptoms: prescribe appropriate analgesics or follow protocol treatment recommended } \\
\text { for urgent cases }\end{array}$ \\
\cline { 2 - 2 } Symptomatic Apical Periodontitis & $\begin{array}{l}\text { Modere symptoms: Follow protocol treatment recommended for urgent cases } \\
\text { Severe symptoms: Follow protocol treatment recommended for urgent cases }\end{array}$ \\
\hline Acute Apical Abscess & $\begin{array}{l}\text { Mild to moderate symptoms and moderate swelling: follow protocol treatment recommended for } \\
\text { urgent cases }\end{array}$ \\
& $\begin{array}{l}\text { Moderate symptoms and fluctuant swelling not causing a threat to systemic health if tooth } \\
\text { restorable: follow protocol treatment recommended for urgent cases }\end{array}$ \\
& $\begin{array}{l}\text { Severe symptoms and infection that has resulted in systemic involvement: incision and } \\
\text { appropriate antibiotics }\end{array}$ \\
\hline Chronic Apical Abscess & $\begin{array}{l}\text { Severe symptoms and soft tissue swelling, infection that may compromise the airway: Hospital } \\
\text { admission, prescribed antibiotics and extraction }\end{array}$ \\
\hline & Mild to moderate symptoms: prescribe appropriate analgesics \\
\hline
\end{tabular}

Table 2. :Protocol for treatment approach to dental traumas in endodontics.

\begin{tabular}{|c|c|}
\hline Complex crown-root fracture & $\begin{array}{l}\text { As an emergency treatment a temporary stabilization of the loose segment to adjacent teeth. In } \\
\text { patients with open apices, it is advantageous to preserve pulp vitality by a partial pulpotomy. This } \\
\text { treatment is also the choice in young patients with completely formed teeth. In patients with mature } \\
\text { apical development, root canal treatment can be the treatment of choice. }\end{array}$ \\
\hline Enamel-dentin-pulp fracture & $\begin{array}{l}\text { In young patients with immature, still developing teeth, it is advantageous to preserve pulp vitality by } \\
\text { pulp capping or partial pulpotomy. Also, this treatment is the choice in young patients with } \\
\text { completely formed teeth. In patients with mature apical development, root canal treatment is usually } \\
\text { the treatment of choice, although pulp capping or partial pulpotomy also may be selected. If tooth } \\
\text { fragment is available, it can be bonded to the tooth. }\end{array}$ \\
\hline Root fracture & $\begin{array}{l}\text { Reposition, if displaced, the coronal segment of the tooth as soon as possible. Check position } \\
\text { radiographically. Stabilize the tooth with a flexible splint for } 4 \text { weeks. If the root fracture is near the } \\
\text { cervical area of the tooth, stabilization is beneficial for a longer period of time (up to } 4 \text { months). }\end{array}$ \\
\hline Subluxation & Normally no treatment is needed \\
\hline Lateral luxation & $\begin{array}{l}\text { Reposition the tooth digitally by disengaging it from its locked position and gently reposition it into } \\
\text { its original location under local anesthesia. }\end{array}$ \\
\hline Extrusive luxation & Reposition the tooth by gently pushing it back into the tooth socket under local anesthesia \\
\hline Intrusive luxation & $\begin{array}{l}\text { Teeth with incomplete root formation: Allow re-eruption without intervention; Teeth with complete } \\
\text { root formation: Allow re-eruption without intervention if the tooth is intruded less than } 3 \mathrm{~mm} \text {. If the } \\
\text { tooth is intruded } 3-7 \mathrm{~mm} \text {, reposition surgically (preferably) or orthodontically. If the tooth is } \\
\text { intruded beyond } 7 \mathrm{~mm} \text {, reposition surgically. }\end{array}$ \\
\hline Avulsion of perman & $\begin{array}{l}\text { Replantation should be performed if the tooth is brought under the conditions that comply with The } \\
\text { International Association of Dental Traumatology standards. }\end{array}$ \\
\hline
\end{tabular}

*The table has been prepared according to the current guideline of The International Association of Dental Traumatology.

nying symptoms such as localized pain on palpation and gingival redness. ${ }^{20}$ It should be kept in mind that dental abscess may lead to sepsis which is a serious infection. ${ }^{21}$ These cases should also be considered urgently.

Dental traumas, mostly affected by maxillary incisors, usually occur in children and adults as a result of falls, physical sports and accidents. Enamel-dentin-pulp fractures, complicated crown-root fractures and root fractures are defined as dental injuries affecting the pulp. ${ }^{22}$ If these conditions are left untreated, it will result in pulp necrosis in the future. In lateral luxation, intrusion, extrusion and avulsion injuries, the periodontal ligament is ruptured with the apical vascular structures. Emergency interventions that can be implemented when these cases consult to the endodontics clinic ${ }^{23}$ are shown in Table 2 .

Patients with chronic diseases such as diabetes mellitus, chronic lung disease and cardiovascular disease, which are risk factors for Covid-19, should be given priority in appointment planning. ${ }^{24}$ Patients should be warned to arrive on time, to wear masks, not to wear any jewelry or accessories, to hide their mobile phones, and to be alone while coming to the appointment. ${ }^{25}$

When it is decided to treat an endodontic emergency, the staff should have prepared all materials and equipment in ad- vance on the appointment date. The dental team should be equipped with disposable N95 masks, gloves, caps, shoe covers, face shields, and gowns (Figure 2). Installing physical barriers in the waiting room and the removal of any unused items is effective in preventing the persistence and spread of the virus during dental care. Similarly, the reception staff who are in close contact with the patient should also wear masks, goggles and protective visors. ${ }^{16,26}$

High fever is one of the clinical signs seen in Covid-19. The body temperature of patients should be measured using a noncontact frontal thermometer or infrared temperature sensors. Normal body temperature is $36.5^{\circ}-37.0^{\circ}$ when measured from the armpit and $35.7^{\circ}-37.5^{\circ}$ when measured from the ear. Patients should wash their hands and then use a hand sanitizer containing $60 \%-95 \%$ alcohol. Eye and foot protection for patients should also be provided to prevent and reduce crossinfection. Images can be used to guide patients. ${ }^{27}$

Dental appointments should include a "safety period" between patients and minimize potential contact with other patients and avoid crowding. If it is inevitable for patients to be together, there should be at least 6 feet $(1.83 \mathrm{~m})$ distance between them. ${ }^{28,29} \mathrm{~A}$ well-ventilated environment is extremely important to minimize the spread of SARS-CoV-2 and other microorganisms. Use a negative pressure unit where the air is 


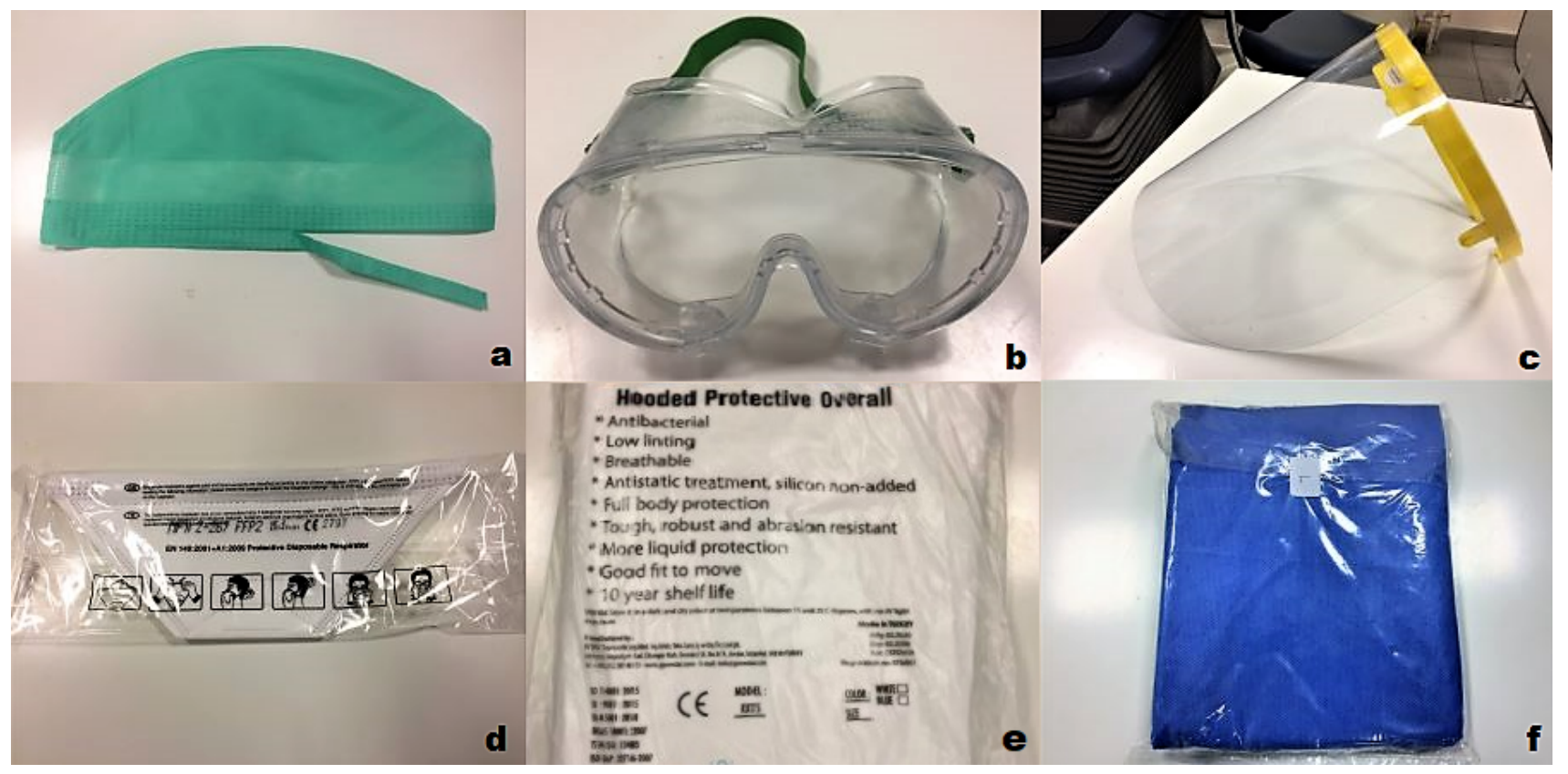

Figure 2. a: cap, b: goggles, c: face shields, d: mask, e: protective overall, f: disposable gown.

immediately subjected to filtering before recirculating provides good ventilation of the dental office. High efficiency air filtering units make it possible to pass the air only in one direction and give the dirty air to the outside. ${ }^{29}$ Thus, it prevents possible virus particles from spreading to the clinic. If this system is not available in clinics, opening a window becomes important. ${ }^{28}$

\section{Approach in endodontic emergencies}

1. Although it is a frequently used mouthwash in dentistry applications, it has been stated that chlorhexidine gluconate is not effective on coronavirus. ${ }^{3}$ If the patient rinses his mouth with a povidoneiodine or hydrogen peroxide-based solution before treatment, the density of microorganisms in the aerosol and droplets decrease. ${ }^{30}$

2. Performing 4-hand applications reduces the risk of contamination. 31

3.To reduce droplets and aerosols, saliva should be taken from the patient with suction, and unasked to spit. ${ }^{31}$

4.Appointment times should be kept as short as possible. ${ }^{16}$

5. A transparent barrier can be used to reduce the aerosol generated during the process. ${ }^{32}$

6. Rubber-dam should be applied before opening the access cavity. The rubber sheet should also cover the patient's nose. 33 The tooth, clamp and dam are cleaned with $3 \% \mathrm{H} 2 \mathrm{O} 2$ and disinfected with $2.5 \% \mathrm{NaOCl}$.

7. When necessary, antireflux valve can be used to reduce pollution in hoses. ${ }^{31}$

8. Ultrasonic use should not be preferred, if necessary, suction with high evacuation, rubber-dam isolation and 4-handed applications should be used. ${ }^{16}$

9. Surgical suction should be close to the tooth and the second one close to the patient's nose to reduce the aerosol. ${ }^{31}$

10. The dental operating microscope can be covered with acetate covers that can be adapted to binocular. Dental loupe and headlights can be adapted onto the face shield. ${ }^{32}$

11. After opening the access cavity, it should be irrigated with $\mathrm{NaOCl} .34$

12. In cases where the pulp is devital and endodontic treatment is required, cone beam computed tomography should be preferred to reduce the risk of contamination and aerosol. Single file systems can be used to shorten the treatment time and reduce the risk of resterilization. ${ }^{19}$ To reduce the recurrent visits of the patient, durable temporary-filling material should be applied and occlusion should be controlled.

13. The situations that the patient may encounter after treatment should be explained. The patient is informed that the pain takes time to pass, the patient should protect the tooth from chewing forces for $24 \mathrm{~h}$ and can use analgesics if necessary. 35

14. Cleaning and disinfection of all surfaces should be done after each patient. In the Ministry of Health COVID-19 Guide, the following are recommended for surface cleaning and disinfection: [1] sodium hypochlorite: for surfaces contaminated with blood and body fluids (1:10 diluted standard bleach); for external surfaces (standard bleach diluted 1: 100); [2] hydrogen peroxide $(0.5 \%)$ : for external surfaces of equipment, floors and walls; [3] tetravalent ammonium compounds: for floors and walls. ${ }^{36}$ All employees involved in the disinfection and decontamination procedure must have personal protective equipment (goggles, masks, gloves). The environment should be free of all unnecessary items to facilitate the cleaning of the clinic after the procedures. ${ }^{27}$ The centers for Disease Control and Prevention reported that the waiting time between patients should be at least $15 \mathrm{~min}$ (20). However, the Office of the Chief Dental Officer England stated that a negative pressure room should be left with the door closed for $20 \mathrm{~min}$ and a neutral pressure room for $1 \mathrm{~h}$ after dental procedures are completed. ${ }^{28,37}$ Simultaneously, in this process, if there are windows opening to the outside in the neutral pressurized room, they can be left open.

The protocols recommended by scientific committees are based on principles that will protect both the patient and physician before, during and after dental treatment. ${ }^{32}$

\section{Conclusion}

Endodontics is a field of dentistry where relatively urgent applications are concentrated. For this reason, since the Covid-19 outbreak started, endodontists in particular have difficulty in delaying treatment. However, the full implementation of the 
recommended treatment approaches and measures may make it possible to overcome this pandemic period with the least damage.

\section{Author Contributions}

Conceptualization B.C.; Data curation E.O.T; Investigation A.O.,E.O.T; Methodology A.O.; Project administration B.C.; Supervision A.O.; Validation E.O.T.; Visualization A.O.; Roles/Writing - original draft E.O.T.,A.O.; Writing - review \& editing B.C.

\section{Conflict of Interest}

The authors of the current article certify that they have no affiliations with any organization or entity with any financial interest.

\section{Authors' ORCID(s)}

A.O. $\quad 0000-0002-3130-0669$

E.O.T. $0000-0003-3669-5062$

B.C. $0000-0001-5645-5029$

\section{References}

1. Chen X, Liao B, Cheng L, Peng X, Xu X, Li Y, et al. The microbial coinfection in COVID-19. Appl Microbiol Biotechnol. 2020;104(18):7777-7785. doi:10.1007/s00253-020-108146.

2. Ather A, Patel B, Ruparel NB, Diogenes A, Hargreaves KM. Coronavirus Disease 19 (COVID-19): Implications for Clinical Dental Care. J Endod. 2020;46(5):584-595. doi:10.1016/j.joen.2020.03.008.

3. Peng $X, X u X$, Li Y, Cheng L, Zhou X, Ren B. Transmission routes of 2019-nCoV and controls in dental practice. Int J Oral Sci. 2020;12(1):9. doi:10.1038/s41368-020-0075-9.

4. Gugnani N, Gugnani S. Safety protocols for dental practices in the COVID-19 era. Evid Based Dent. 2020;21(2):56-57. doi:10.1038/s41432-020-0094-6.

5. Bidar M, Gharechahi $M$, Soleimani T, Eslami N. A Survey over the Dentists' and Endodntists' Approaches towards the Management of Endodontic Emergencies in Mashhad, Iran. Iran Endod J. 2015;10(4):256-262. doi:10.7508/iej.2015.04.010.

6. Drum M, Reader A, Nusstein J, Fowler S. Successful pulpal anesthesia for symptomatic irreversible pulpitis. J Am Dent Assoc. 2017;148(4):267-271. doi:10.1016/j.adaj.2017.01.002.

7. Cope AL, Francis N, Wood F, Chestnutt IG. Systemic antibiotics for symptomatic apical periodontitis and acute apical abscess in adults. Cochrane Database Syst Rev. 2018;9(9):Cd010136. doi:10.1002/14651858.CD010136.pub3.

8. Sipavičiūtė E, Manelienè R. Pain and flare-up after endodontic treatment procedures. Stomatologija. 2014;16(1):25-30.

9. Korolenkova MV, Rakhmanova MS. [Outcomes of traumatic dental injuries in children]. Stomatologiia (Mosk). 2019;98(4):116-122. doi:10.17116/stomat201998041116.

10. Pascarella G, Strumia A, Piliego C, Bruno F, Del Buono R, Costa F, et al. COVID-19 diagnosis and management: a comprehensive review. J Intern Med. 2020;288(2):192-206. doi:10.1111/joim.13091.

11. Zhao Y, Zhao Z, Wang Y, Zhou Y, Ma Y, Zuo W. Single-cell
RNA expression profiling of ACE2, the putative receptor of Wuhan 2019-nCov. BioRxiv. 2020.

12. Sun $\mathrm{P}, \mathrm{Lu} X, \mathrm{Xu} C$, Sun W, Pan B. Understanding of COVID19 based on current evidence. J Med Virol. 2020;92(6):548551. doi:10.1002/jmv.25722.

13. Ahn DG, Shin HJ, Kim MH, Lee S, Kim HS, Myoung J, et al. Current Status of Epidemiology, Diagnosis, Therapeutics, and Vaccines for Novel Coronavirus Disease 2019 (COVID-19). J Microbiol Biotechnol. 2020;30(3):313-324. doi:10.4014/jmb.2003.03011.

14. Li H, Liu SM, Yu XH, Tang SL, Tang CK. Coronavirus disease 2019 (COVID-19): current status and future perspectives. Int J Antimicrob Agents. 2020;55(5):105951. doi:10.1016/j.ijantimicag.2020.105951.

15. Pourbagheri-Sigaroodi A, Bashash D, Fateh F, Abolghasemi $\mathrm{H}$. Laboratory findings in COVID-19 diagnosis and prognosis. Clin Chim Acta. 2020;510:475-482. doi:10.1016/j.cca.2020.08.019.

16. Association AD. ADA releases interim guidance on minimizing COVID-19 transmission risk when treating dental emergencies: resources discuss how to proceed before, during, after treatment. Orlando, EUA: ADA News. 2020.

17. Torabinejad M, Walton RE. Endodontics: Principles and Practice. St. Louis: Saunders. Elsevier; 2009.

18. Patel B. Endodontic diagnosis, pathology and treatment planning. Classification of pulp and perio-apical disease Switzerland: Springer International Publishing. 2015.

19. Yu J, Zhang T, Zhao D, Haapasalo M, Shen Y. Characteristics of Endodontic Emergencies during Coronavirus Disease 2019 Outbreak in Wuhan. J Endod. 2020;46(6):730735. doi:10.1016/j.joen.2020.04.001.

20. Sanders JL, Houck RC. In: Dental Abscess. Treasure Island (FL): StatPearls Publishing Copyright (C) 2020, StatPearls Publishing LLC.; 2020. .

21. Mannan S, Tordik PA, Martinho FC, Chivian N, Hirschberg CS. Dental Abscess to Septic Shock - A Case Report and Literature Review. J Endod. 2021. doi:10.1016/j.joen.2020.12.016

22. Sanaei-Rad P, Hajihassani N, Jamshidi D. Management of a complex traumatic dental injury: Crown, crown-root, and root fracture. Clin Case Rep. 2020;8(12):2504-2509. doi:10.1002/ccr3.3191.

23. Bourguignon $\mathrm{C}$, Cohenca $\mathrm{N}$, Lauridsen $\mathrm{E}$, Flores $\mathrm{MT}$, O'Connell AC, Day PF, et al. International Association of Dental Traumatology guidelines for the management of traumatic dental injuries: 1. Fractures and luxations. Dental Traumatology. 2020;36(4):314-330. doi:https://doi.org/10.1111/edt.12578.

24. Garg S. Hospitalization rates and characteristics of patients hospitalized with laboratory-confirmed coronavirus disease 2019-COVID-NET, 14 States, March 1-30, 2020. MMWR Morbidity and mortality weekly report. 2020;69.

25. Clarkson J, Ramsay C, Aceves M, Brazzelli M, Colloc T, Dave $\mathrm{M}$, et al.. Recommendations for the re-opening of dental services: a rapid review of international sources [Journal Article]; 2020.

26. Coronavirus disease (COVID-19) [Web Page]; 2020. Available from: https://www.who.int/emergencies/diseases/ novel-coronavirus-2019/question-and-answers-hub/ q-a-detail/coronavirus-disease-covid-19.

27. How COVID-19 Spreads [Web Page]; 2020. Available from: https://www.cdc.gov/coronavirus/2019-ncov/about/ transmission.html.

28. Standard operating procedure. Transition to recovery [Web Page]; 2020. Available from: https://www.england. nhs.uk/coronavirus/wp-content/uploads/sites/52/2020/06/ C0575-dental-transition-to-recovery-SOP-4June.pdf.

29. Guidance for Dental Settings [Web Page]; 2020. Avail- 
able from: https://www.cdc.gov/coronavirus/2019-ncov/ hcp/dental-settings.html.

30. Vergara-Buenaventura A, Castro-Ruiz C. Use of mouthwashes against COVID-19 in dentistry. $\mathrm{Br} J$ Oral Maxillofac Surg. 2020;58(8):924-927. doi:10.1016/j.bjoms.2020.08.016.

31. Meng L, Hua F, Bian Z. Coronavirus Disease 2019 (COVID-19): Emerging and Future Challenges for Dental and Oral Medicine. J Dent Res. 2020;99(5):481-487. doi:10.1177/0022034520914246.

32. Silva WO, Vianna Silva Macedo RP, Nevares G, Val Rodrigues RC, Grossi Heleno JF, Braga Pintor AV, et al. Recommendations for Managing Endodontic Emergencies during Coronavirus Disease 2019 Outbreak. J Endod. 2021;47(1):310. doi:10.1016/j.joen.2020.09.018.

33. Kampf G, Todt D, Pfaender S, Steinmann E. Persistence of coronaviruses on inanimate surfaces and their inactivation with biocidal agents. J Hosp Infect. 2020;104(3):246-251. doi:10.1016/j.jhin.2020.01.022.

34. Verma N, Sangwan P, Tewari S, Duhan J. Effect of Dif- ferent Concentrations of Sodium Hypochlorite on Outcome of Primary Root Canal Treatment: A Randomized Controlled Trial. J Endod. 2019;45(4):357-363. doi:10.1016/j.joen.2019.01.003.

35. Diagnosis and Management of Endodontic Emergencies, a British Endodontic Society Position Paper for Primary Dental Care and other healthcare providers during the COVID19 pandemic [Web Page]; 2020. Available from: https: //britishendodonticsociety.org.uk/wp-content/uploads/ 2020/04/BES-Emergency-Protocol-v3-April-23-1.pdf.

36. Cleaning and disinfection of environmental surfaces in the context of COVID-19: interim guidance, 15 May 2020; 2020. Available from: https://apps.who.int/iris/handle/10665/ 332096.

37. Martins-Filho PR, de Gois-Santos VT, Tavares CSS, de Melo EGM, do Nascimento-Júnior EM, Santos VS. Recommendations for a safety dental care management during SARS-CoV-2 pandemic. Rev Panam Salud Publica. 2020;44:e51. doi:10.26633/rpsp.2020.51. 